\title{
RESEARCH
}

Open Access

\section{Various forms of alcohol use and their predictors among pregnant women in post conflict northern Uganda: a cross sectional study}

Apophia Agiresaasi ${ }^{1 *}$ (D), Goretti Nassanga ${ }^{2}$, Gakenia Wamuyu Maina ${ }^{1}$, Juliet Kiguli ${ }^{1}$, Elizabeth Nabiwemba ${ }^{1}$ and Nazarius Mbona Tumwesigye ${ }^{1}$

\begin{abstract}
Background: Alcohol use during pregnancy has been associated with several births and developmental disorders. This study set out to determine the various forms of alcohol consumption among pregnant women and their predictors in post conflict Northern Uganda.

Methods: In the months of May to June 2019, we conducted a cross sectional study among 420 pregnant women seeking antenatal care services at both Government and private health facilities in Gulu, Kitgum and Pader districts in Northern Uganda. We asked them about consumption of various alcoholic beverages. A three stage stratified cluster sampling approach was used and study participants randomly selected from health facilities of interest. We used descriptive statistics to estimate the prevalence of various forms of alcohol use. The chi- square test and logistic regression were used to assess associations of alcohol use among respondents and their socio demographic and other characteristics.

Results: Overall 99 women (23.6\%) reported current alcohol use (any amount). Up to $11 \%(N=11)$ of all drinkers were identified by the AUDIT to be women with problem drinking behavior, $8 \%(N=8)$ of women reported hazardous drinking and only four (4\%) were women with active alcohol dependent behavior. Predictors of maternal alcohol use included pre-pregnancy alcohol consumption, knowledge, attitude, education level, parity and residence.

Conclusions: This study indicates that alcohol use (any mount) during pregnancy is high while alcohol dependence, problematic and hazardous drinking is low. Knowledge and attitude were important predictors of alcohol use. While alleviating alcohol use, development partners and relevant government departments should consider communication and other interventions that increase knowledge and risk perception on maternal drinking. Other risk factors that predict maternal drinking such as prior alcohol use, residence and parity should be mitigated or eliminated.
\end{abstract}

Keywords: Alcohol use, Pregnancy, Antenatal care, Post conflict, Uganda

\footnotetext{
*Correspondence: agiresaasi@gmail.com

'College of Health Sciences, Makerere School of Public Health, Kampala, Uganda

Full list of author information is available at the end of the article
}

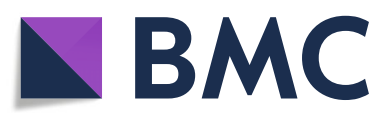

(- The Author(s). 2021 Open Access This article is licensed under a Creative Commons Attribution 4.0 International License, which permits use, sharing, adaptation, distribution and reproduction in any medium or format, as long as you give appropriate credit to the original author(s) and the source, provide a link to the Creative Commons licence, and indicate if changes were made. The images or other third party material in this article are included in the article's Creative Commons licence, unless indicated otherwise in a credit line to the material. If material is not included in the article's Creative Commons licence and your intended use is not permitted by statutory regulation or exceeds the permitted use, you will need to obtain permission directly from the copyright holder. To view a copy of this licence, visit http://creativecommons.org/licenses/by/4.0/. The Creative Commons Public Domain Dedication waiver (http://creativecommons.org/publicdomain/zero/1.0/) applies to the data made available in this article, unless otherwise stated in a credit line to the data. 


\section{Background}

Uganda has the 7th highest rate of alcohol consumption in the Africa region according to the World Health organisation (WHO) (2018) report [1]. More so, some studies in Uganda have recorded higher prevalence of alcohol use in the general population in post conflict Northern Uganda compared to other regions in the country [2-4]. This has been attributed to armed banditry and traumatic stress resulting from the two- decade civil war between the Lord's resistance Army and the Government of Uganda that displaced $90 \%$ of the region's population [5]. It also disrupted the socio economic set up rendering many homeless and jobless [6]. After the war many women resorted to making alcohol as a source of livelihood given the demand for it but also to treat depression resulting from the war [7] Alcohol is also part and parcel of social gatherings in these communities and women, given their socially ascribed roles as caretakers are involved in serving and preparation hence at risk of using or abusing alcohol even during pregnancy [8]. Worse still, the vast majority (84\%) of people in Northern Uganda are living below the poverty line [9] which is four times higher than the national average of $20 \%$. The relationship between alcohol use, poverty and war has been well established. Because of these associations, we hypothesize that pregnant mothers in the lowest wealth quintile from conflict affected areas are more likely to drink than their other contemporaries. This has a bearing on the health of the mother and the baby.

Alcohol use during pregnancy has been linked to pre term births (PTB), stillbirths, low birth weight (LBW) several birth defects and developmental disabilities known as Fetal Alcohol Spectrum Disorders (FASD) [10, 11].Todate, the World Health Organization recommends that pregnant women should completely abstain from alcohol as no amount of alcohol is considered safe for pregnancy [12]. Despite such recommendations Alcohol use among women in Africa is not uncommon.

In South Africa, prevalence of alcohol use (any amount) among pregnant women ranged from 3.2\% in Johannesburg to $42.8 \%$ in Western Cape [13-15].. In Nigeria, prevalence varied from state to state. It ranged from $2.6 \%$ in Ogun state to $59.28 \%$ in South South Nigeria [16-19]. In Ghana, Bosomtwe district drinking (any amount) during pregnancy was reported at $20.4 \%$ [20] and $14.6 \%$ by another study [21]. In Eastern Africa, maternal alcohol use (any amount) varies. A recent study reported alcohol use during pregnancy at $15.1 \%$ in Dodoma Tanzania [22]. In Ethiopia maternal alcohol use was reported at 34\% [23]. Whereas some studies have documented alcohol use during pregnancy in some parts of Africa, data for maternal alcohol use during pregnancy in post conflict settings remains notably scarce.
A systematic review and country specific studies have documented predictors of alcohol use during pregnancy across the world. Factors found to predict drinking during pregnancy include knowledge and attitude [24, 25] having disposable income [26], having a partner or friend who drinks [27] and Pre-pregnancy alcohol consumption [27-29]. Women with more children or higher number of previous pregnancies were more likely to drink during pregnancy than those with fewer children/ pregnancies [30-32] .Being employed, having a higher income and higher social status have been reported to predict maternal drinking during pregnancy [31, 33]. Women with higher education were less likely to drink than women with less education [31].

In most maternal alcohol use related studies, predictors of alcohol use (any amount) have been examined. However predictors of frequent and or heavy alcohol use have not been assessed yet higher levels of alcohol use has been particularly associated with adverse effects on pregnancy. Without such data, it is difficult to adequately plan for any targeted alcohol exposed pregnancy interventions. To address this gap, this study investigated the prevalence of various forms of alcohol use during pregnancy and their predictors in post conflict northern Uganda.

\section{Methods}

\section{Study area and design}

From the month of May to June 2019, we conducted a cross sectional study of women attending the antenatal care at selected health facilities in Gulu, Kitgum and Pader districts in Post Conflict Northern Uganda. Gulu, Kitgum and Pader districts are served by 67, 28 and 19 public, private for profit and Private not for Profit health facilities providing Antenatal Care (ANC) services respectively. Agriculture is the main source of livelihood for locals in the three districts. Gulu district was the epicentre of much of the fighting between the Ugandan army and the Lord's Resistance Army (LRA). Kitgum and Pader districts also suffered many deaths and social disruption resulting from the two decade civil war that plagued the region.

We calculated the sample size using the Kish Lesley formulae. The degree of accuracy was set at 0.05 , with estimated prevalence of alcohol consumption put at $30 \%$. The minimum required sample size for the study was determined to be 322.6 but increased to 420 to cater for design effect.

This study used a multi stage cluster sampling method. Acholi sub-region was stratified into 8 regions consisting the 8 districts in the region. Simple random sampling was used to select the three districts of Gulu, Kitgum and Pader from the 8 districts in Acholi sub-region using paper lots. At the second stage, the health facilities 
providing antenatal care services in the three districts were randomly selected. For purposes of representativeness, all categories of health facilities in a given stratum were catered for. At the third stage, in each of the strata, the required number of respondents by health facility category were obtained randomly from the available facilities of the category of interest using systematic random sampling with the starting point obtained by simple ballot.

We evaluated Antenatal care attendees for eligibility and willingness to participate in the interview. To be eligible, women had to be at least 15 years old, at least be 8 weeks to 36 weeks gestation as estimated from the last normal menstrual period. Ability to speak any of the Acholi languages and or English. All those selected and willing to participate in the study were interviewed after having sought ANC services.

Data was collected using a computerized, Internetbased survey tool - Open Data Kit (ODK) and tablet computers fitted with checks. During the interview we asked women about alcohol consumption (any amount and any type). Frequency and quantity of alcohol consumed was also captured. This study assessed alcohol related problems using the World Health Organization' Alcohol Use Disorders Identification Test (AUDIT) questionnaire which was administered as an oral interview. This tool is a 10-item self-report instrument that includes quantity and frequency of alcohol use and is designed to identify individuals currently experiencing alcohol problems [34]. Both the structured questionnaire and the AUDIT Questionnaire were piloted in neighboring Amuru district. The following measures were taken as one standard drink. i) a 285-ml bottle or can of beer, (ii) a 120-ml glass of wine (factory distilled or locally brewed), and [3] a 30-ml glass/tot of a spirit or gin (factory distilled or locally brewed). The questions in the AUDIT questionnaire were revised to reflect alcohol consumption by respondents since onset of pregnancy.

We interviewed women about their Socio demographic characteristics such as maternal age at first birth, level of education, marital status, occupation, age, level of income, residence, occupation, parity, religion, history of miscarriage, recreational drug use, smoking and other personal habits. We also asked women questions about their risk perception of using alcohol, knowledge of dangers of maternal drinking, past related behavior (pre-pregnancy alcohol use and sexual behaviors). Adequate knowledge was assumed if a woman mentioned 4 or more effects of alcohol, those who mention 2-3 effects were assumed to have fair knowledge and those who mention $0-1$ were categorized as having poor knowledge.

\section{Data management and analysis}

Data were cleaned and exported to Statistical Package for Social Sciences (SPSS) where coding and analysis was done. In the first stage of analysis, descriptive statistics were used to estimate the prevalence of various forms of alcohol use. The chi- square test was used to compare the drinking status of studied subjects with their socio - demographic and other characteristics. We did not do analyses for complex samples. For variables where expected count was less than 5 we reported the Fisher's exact test $p$-value not the p-value from the chisquare test . Variables found to be significant at $P \leq 0.05$ in the bivariate analyses were further modelled into the multiple logistic regression analysis.

Regarding the Audit, the hazardous alcohol use (questions 1 to 3 ) cut-off point was put at 6 . The dependence (questions 4 to 6 ) cut-off was 4 and the harmful use (questions 7 to 10 ) cutoff was 7 points. Scores $\geq 8$ were considered an indicator of problematic alcohol use [35].

Study participants were categorized as abstainers if they did not report alcohol consumption since on-set of pregnancy. Forms of alcohol consumption were 1) Light infrequent drinkers (those who reported alcohol use during current pregnancy but never took 4 drinks at any time), 2) Heavy infrequent drinkers (those who reported drinking 4 drinks less than monthly during current pregnancy), 3) Heavy moderately frequent drinking (reported drinking at least 4 or more drinks on an occasion at least monthly), 4) Heavy frequent drinking (reported drinking 4 drinks on an occasion at least weekly) and 5) Heavy regular drinking(reported drinking at least 4 drinks almost daily).

This study was approved by the Makerere University School of Public Health Institutional Review Board and the Uganda National Council for Science and Technology (UNCST) Ref SS 4938. Study participants were assured of the confidentiality of their responses and their written informed consent was sought before the interviews commenced. They were informed that they could choose not to answer any questions that they were not comfortable with or could withdraw from the interview at any time. In addition, the study sought clearance from the office of the District Health Officers (DHO) in each of the three districts of Gulu, Kitgum and Pader.

\section{Results}

\section{Characteristics of study participants}

Overall, 420 eligible women attending ANC in selected health facilities in Gulu, Kitgum and Pader districts in Northern Uganda participated in the study. Majority were aged $21-25(56.2 \%)$. Up to $88.1 \%(N=370)$ were either formally married of cohabiting. Sixty percent $(N=$ 252) were Catholics. Slightly more than half $(56.4 \% ; N=$ 237) had attained primary level of education. Up to $57.9 \%(N=243)$ were from rural areas. Most $(N=308$; $73.3 \%$ ) had a job from which they earned some income 
of whom $(186 ; 44.3 \%)$ were farmers. This is presented in Table 1.

More than half $(N=225 ; 53.6 \%)$ were in second trimester of pregnancy and majority $(N=379 ; 90.2 \%)$ reported having one sexual partner in the last 1 year preceding the survey. Fewer women reported having ever had a premature birth $(N=30 ; 7.1 \%)$, an underweight baby $(N=25 ; 6.0 \%)$ or a still birth $(N=23 ; 5.5 \%)$. About a half $(54.8 \% ; N=177)$ had at least two live children. Only three $(0.7 \%)$ women had ever smoked or used tobacco while only two $(0.5 \%)$ had ever used marijuana or other types of drugs. Poor knowledge (mentioned 0 to 1 effect of alcohol on mother and baby) was reported by $(N=234(55.7 \%)$, fair knowledge (mentioned 2 to 3 effects of alcohol on mother and baby) by $41.9 \%$ and adequate knowledge (mentioned 4 or more effects of alcohol on mother and baby) by $2.4 \%$. Slightly more than half the respondents had positive attitudes (Said alcohol was extremely important/very important in increasing health risks to mother and baby) $(N=228,54.3 \%)$, few respondents had fair attitudes towards maternal alcohol use (said alcohol was moderately important in increasing health risks to mother and baby) $(N=58,13.8 \%)$ and 134 respondents had Negative attitudes (said alcohol was not at all important /slightly important in increasing health risks to the mother and the baby (31.9\%). Health workers were the most common source of information on drinking during pregnancy $(N=178,75.1 \%)$

Table 1 Showing demographic characteristics of respondents and their drinking patterns

\begin{tabular}{|c|c|c|c|c|c|c|c|c|c|c|c|}
\hline \multirow[b]{3}{*}{ Age Group } & \multirow[b]{3}{*}{$15-20$} & \multicolumn{8}{|c|}{ ALCOHOL DRINKING } & \multirow{3}{*}{$\begin{array}{l}\text { Chi-square/ } \\
\text { fishers test }\end{array}$} & \multirow[t]{3}{*}{$p$-value } \\
\hline & & \multicolumn{2}{|c|}{$\begin{array}{l}\text { Never } \\
\text { drank }\end{array}$} & \multicolumn{2}{|c|}{$\begin{array}{l}\text { Ever } \\
\text { drank }\end{array}$} & \multicolumn{2}{|c|}{$\begin{array}{l}\text { Currently } \\
\text { consuming } \\
\text { Alcohol }\end{array}$} & \multicolumn{2}{|c|}{ Total } & & \\
\hline & & 67 & $60.9 \%$ & 22 & $20.0 \%$ & 21 & $19.1 \%$ & 110 & $100.0 \%$ & & \\
\hline & $21-25$ & 59 & $46.8 \%$ & 43 & $34.1 \%$ & 24 & $19.0 \%$ & 126 & $100.0 \%$ & $26.018^{\mathrm{a}}$ & .001 \\
\hline & $26-30$ & 39 & $37.1 \%$ & 40 & $38.1 \%$ & 26 & $24.8 \%$ & 105 & $100.0 \%$ & & \\
\hline & $31-35$ & 22 & $38.6 \%$ & 18 & $31.6 \%$ & 17 & $29.8 \%$ & 57 & $100.0 \%$ & & \\
\hline & $36-45$ & 6 & $27.3 \%$ & 5 & $22.7 \%$ & 11 & $50.0 \%$ & 22 & $100.0 \%$ & & \\
\hline \multirow[t]{5}{*}{ Highest Level of Education Attained } & No formal education & 18 & $41.9 \%$ & 8 & $18.6 \%$ & 17 & $39.5 \%$ & 43 & $100.0 \%$ & $17.996^{\mathrm{a}}$ & .006 \\
\hline & Primary & 119 & $50.2 \%$ & 70 & $29.5 \%$ & 48 & $20.3 \%$ & 237 & $100.0 \%$ & & \\
\hline & Secondary & 47 & $46.5 \%$ & 31 & $30.7 \%$ & 23 & $22.8 \%$ & 101 & $100.0 \%$ & & \\
\hline & Higher & 9 & $23.1 \%$ & 19 & $48.7 \%$ & 11 & $28.2 \%$ & 39 & $100.0 \%$ & & \\
\hline & Total & 75 & $47.8 \%$ & 61 & $38.9 \%$ & 21 & $13.4 \%$ & 420 & $100.0 \%$ & & \\
\hline \multirow[t]{5}{*}{ Marital Status } & Married & 7 & $25.0 \%$ & 3 & $10.7 \%$ & 18 & $64.3 \%$ & 157 & $100.0 \%$ & & \\
\hline & Single/separated/divorced & 98 & $46.0 \%$ & 56 & $26.3 \%$ & 59 & $27.7 \%$ & 28 & $100.0 \%$ & 43.825 & $<.000$ \\
\hline & Cohabiting & 13 & $59.1 \%$ & 8 & $36.4 \%$ & 1 & $4.5 \%$ & 213 & $100.0 \%$ & & \\
\hline & Other & 109 & $43.3 \%$ & 81 & $32.1 \%$ & 62 & $24.6 \%$ & 22 & $100.0 \%$ & & \\
\hline & Total & 44 & $41.9 \%$ & 33 & $31.4 \%$ & 28 & $26.7 \%$ & 420 & $100.0 \%$ & & \\
\hline \multirow[t]{5}{*}{ Religion } & Catholic & 10 & $71.4 \%$ & 2 & $14.3 \%$ & 2 & $14.3 \%$ & 252 & $100.0 \%$ & & \\
\hline & Protestant & 30 & $61.2 \%$ & 12 & $24.5 \%$ & 7 & $14.3 \%$ & 105 & $100.0 \%$ & 9.389 & .146 \\
\hline & Muslim & 112 & $46.1 \%$ & 65 & $26.7 \%$ & 66 & $27.2 \%$ & 14 & $100.0 \%$ & & \\
\hline & Pentecostal & 71 & $45.5 \%$ & 60 & $38.5 \%$ & 25 & $16.0 \%$ & 49 & $100.0 \%$ & & \\
\hline & Total & 10 & $47.6 \%$ & 3 & $14.3 \%$ & 8 & $38.1 \%$ & 420 & $100.0 \%$ & & \\
\hline \multirow[t]{4}{*}{ Residence } & Rural & 84 & $45.2 \%$ & 51 & $27.4 \%$ & 51 & $27.4 \%$ & 243 & $100.0 \%$ & & \\
\hline & urban & 55 & $64.7 \%$ & 20 & $23.5 \%$ & 10 & $11.8 \%$ & 147 & $100.0 \%$ & 13.245 & .009 \\
\hline & Small town/village & 26 & $37.7 \%$ & 26 & $37.7 \%$ & 17 & $24.6 \%$ & 21 & $100.0 \%$ & & \\
\hline & Big town/city & 28 & $35.0 \%$ & 31 & $38.8 \%$ & 21 & $26.3 \%$ & 9 & $100.0 \%$ & & \\
\hline \multirow[t]{4}{*}{ Occupation } & Farmer & 84 & $43.5 \%$ & 51 & $39.8 \%$ & 51 & $51.5 \%$ & 186 & $100.0 \%$ & & \\
\hline & Housewife & 55 & $28.5 \%$ & 20 & $15.6 \%$ & 10 & $10.1 \%$ & 85 & $100.0 \%$ & 21.01 & .002 \\
\hline & Retail business & 26 & $13.5 \%$ & 26 & $20.3 \%$ & 17 & $17.2 \%$ & 69 & $100.0 \%$ & & \\
\hline & Other & 25 & $13.0 \%$ & 21 & $16.4 \%$ & 18 & $18.2 \%$ & 64 & $100.0 \%$ & & \\
\hline
\end{tabular}


followed by friends $(N=65,27.4 \%$. This is presented in Table 2.

\section{Types of alcohol consumed, frequency and amount consumed}

Of the 420 women surveyed, 194 (46.2\%) reported lifetime alcohol abstinence. Slightly more than half $(N=$ 226 ; $53.8 \%$ ) reported that they have ever consumed alcohol, of these, 99 women (23.6\%) reported alcohol use during current pregnancy and 10\% $(N=33)$ reported that they stopped alcohol consumption after pregnancy recognition. The most common type of alcohol consumed was kwete (fermented maize and millet; ABV unknown) drunk by 50 women (50.5\%) followed by beer drunk by 38 women (38.4\%) (4-6\% ABV). Twelve (12.1\%) women drunk Arege (ABV unknown), seven drunk Lujulu (Fermented cassava, Sorghum and Maize; ABV unknown). Six consumed local waragi (ABV unknown). Two (2.0\%) consumed dete (ABV unknown) and two $(2.0 \%)$ consumed wine $(12.5 \%$ ABV). Nine women $(9.1 \%)$ consumed other alcoholic beverages. Up to $24.2 \%$ of alcohol consumers reported drinking two or more beverage types.

Among current drinkers, $(N=29 ; 29.3 \%)$ reported that they drink 3 to 4 drinks in a day. 69(69.1\%) consumed 1 or 2 drinks in day. When asked how often they drunk 6 or more drinks on an occasion; $(N=14 ; 13.7 \%)$ said less than monthly, $(N=8 ; 7.1 \%)$ said monthly and $(N=2$; $2 \%)$ said weekly.

A typology of drinkers was estimated [36] . Respondents were asked how often they consumed 4 or more drinks in a day; 33(33.3\%) were light infrequent drinkers (reported alcohol use during current pregnancy but never took 4 drinks at any time), 29 participants (29.3\%) reported heavy infrequent drinking (took 4 drinks less than monthly during current pregnancy), 24(24.2\%), reported heavy moderately frequent drinking (drunk at least 4 or more drinks on an occasion at least monthly). Heavy frequent drinking(drinking 4 drinks on an occasion at least weekly) and heavy regular drinking(drinking at least 4 drinks almost daily) was less commonly reported by $11(11.1 \%)$ and (2\%)respectively.

Table 2 Showing knowledge, attitudes and Gynaecologic characteristics of respondents and their drinking patterns

\begin{tabular}{|c|c|c|c|c|c|c|c|c|c|c|c|}
\hline \multirow[b]{3}{*}{ Live Children } & \multirow[b]{3}{*}{ One } & \multicolumn{8}{|c|}{ ALCOHOL DRINKING } & \multirow{3}{*}{$\begin{array}{l}\text { Chi- } \\
\text { square }\end{array}$} & \multirow[t]{3}{*}{$p$-value } \\
\hline & & \multicolumn{2}{|c|}{ Never drank } & \multicolumn{2}{|c|}{ Ever drank } & \multicolumn{2}{|c|}{ Currently consuming Alcohol } & \multicolumn{2}{|c|}{ Total } & & \\
\hline & & 36 & $42.9 \%$ & 30 & $35.7 \%$ & 18 & $21.4 \%$ & 84 & $100.0 \%$ & & \\
\hline & Two & 41 & $44.1 \%$ & 37 & $39.8 \%$ & 15 & $16.1 \%$ & 93 & $100.0 \%$ & $16.748^{\mathrm{a}}$ & .0328 \\
\hline & Three & 38 & $45.2 \%$ & 25 & $29.8 \%$ & 21 & $25.0 \%$ & 84 & $100.0 \%$ & & \\
\hline & Four & 13 & $34.2 \%$ & 11 & $28.9 \%$ & 14 & $36.8 \%$ & 38 & $100.0 \%$ & & \\
\hline & Five+ & 8 & $33.3 \%$ & 4 & $16.7 \%$ & 12 & $50.0 \%$ & 24 & $100.0 \%$ & & \\
\hline \multirow[t]{3}{*}{ Trimester } & First trimester & 56 & $50.9 \%$ & 38 & $34.5 \%$ & 16 & $14.5 \%$ & 110 & $100.0 \%$ & & \\
\hline & Second trimester & 100 & $44.4 \%$ & 56 & $24.9 \%$ & 69 & $30.7 \%$ & 225 & $100.0 \%$ & $16.666^{\mathrm{a}}$ & .0022 \\
\hline & Third trimester & 37 & $43.5 \%$ & 34 & $40.0 \%$ & 14 & $16.5 \%$ & 85 & $100.0 \%$ & & \\
\hline \multirow{2}{*}{$\begin{array}{l}\text { Sex Partners they have had in the } \\
\text { last twelve months }\end{array}$} & One & 181 & $47.8 \%$ & 123 & $32.5 \%$ & 75 & $19.8 \%$ & 379 & $100.0 \%$ & 31.3 & $<0.000$ \\
\hline & Two or more & 12 & $29.3 \%$ & 5 & $12.2 \%$ & 24 & $58.5 \%$ & 41 & $100.0 \%$ & & \\
\hline \multirow{2}{*}{$\begin{array}{l}\text { Knowledge of anything that could } \\
\text { Harm baby during pregnancy }\end{array}$} & Yes & 131 & $45.8 \%$ & 100 & $35.0 \%$ & 55 & $19.2 \%$ & 286 & $100.0 \%$ & 13.096 & 0.001 \\
\hline & No & 62 & $46.3 \%$ & 28 & $20.9 \%$ & 44 & $32.8 \%$ & 134 & $100.0 \%$ & & \\
\hline \multirow{3}{*}{$\begin{array}{l}\text { Attitude/perception of alcohol in } \\
\text { increasing chances of health risks } \\
\text { for wmn and babies }\end{array}$} & Negative attitude & 49 & $36.6 \%$ & 21 & $15.7 \%$ & 64 & $47.8 \%$ & 134 & $100.0 \%$ & 68.498 & $<0.000$ \\
\hline & Fair attitude & 25 & $43.1 \%$ & 23 & $39.7 \%$ & 10 & $17.2 \%$ & 58 & $100.0 \%$ & & \\
\hline & Positive attitude & 119 & $52.2 \%$ & 84 & $36.8 \%$ & 25 & $11.0 \%$ & 228 & $100.0 \%$ & & \\
\hline \multirow{3}{*}{$\begin{array}{l}\text { Knowledge of the dangers of } \\
\text { alcohol use during pregnancy }\end{array}$} & Poor knowledge & 98 & $41.9 \%$ & 59 & $25.2 \%$ & 77 & $32.9 \%$ & 234 & $100.0 \%$ & 27.08 & $<0.000$ \\
\hline & Fair knowledge & 89 & $50.6 \%$ & 65 & $36.9 \%$ & 22 & $12.5 \%$ & 176 & $100.0 \%$ & & \\
\hline & Adequate & 6 & $60.0 \%$ & 4 & $40.0 \%$ & 0 & $0.0 \%$ & 10 & $100.0 \%$ & & \\
\hline \multirow{2}{*}{$\begin{array}{l}\text { My Family would not approve of } \\
\text { me drinking while pregnant }\end{array}$} & Disagree & 13 & $22.0 \%$ & 4 & $6.8 \%$ & 42 & $71.2 \%$ & 59 & $100.0 \%$ & 87.216 & $<0.000$ \\
\hline & Agree & 180 & $49.9 \%$ & 124 & $34.3 \%$ & 57 & $15.8 \%$ & 361 & $100.0 \%$ & & \\
\hline \multirow{2}{*}{$\begin{array}{l}\text { My Friends and Community wld } \\
\text { approve of me drinking when } \\
\text { pregnant }\end{array}$} & Disagree & 178 & $48.4 \%$ & 125 & $34.0 \%$ & 65 & $17.7 \%$ & 368 & $100.0 \%$ & 59.689 & $<0.000$ \\
\hline & Agree & 15 & $28.8 \%$ & 3 & $5.8 \%$ & 34 & $65.4 \%$ & 52 & $100.0 \%$ & & \\
\hline
\end{tabular}

${ }^{a}$ About a half of the respondents were in their second trimester of pregnancy, $22 \%$ had two live children. An overwhelming majority reported one sex partner in last twelve months preceding the survey. Most respondents agreed that their family and friends would not approve of them drinking during pregnancy 
Up to $11 \%(N=11)$ of all drinkers were identified by the AUDIT to be women with problematic alcohol use, $8 \%(N=8)$ reported hazardous drinking and only four (4\%) were women with alcohol dependence.

Almost a third of drinkers (29.3\%) reported binge drinking less than monthly during pregnancy. Up to $24.2 \%$, reported binging at least monthly. Weekly and daily binging was reported by $11(11.1 \%)$ and $(2 \%)$ of drinkers respectively.

\section{Factors associated with alcohol consumption during pregnancy}

Maternal alcohol consumption was associated with older age $(P=0.014)$, lack of formal education $(P=0.045)$ and pre-pregnancy alcohol consumption $(P<0.001)$. Knowledge was also associated with alcohol use during pregnancy. Women who reported that they have never received any information on drinking during pregnancy were more likely to drink during pregnancy $(\mathrm{P}<0.001)$ as were women who said they had no knowledge of anything that could harm baby during pregnancy $(P=$ 0.002). Gynecological factors associated with alcohol use during pregnancy include having a live birth $(P=0.004)$ and being in the second trimester $(P=0.001)$. Attitudes, prior and current behavior were strongly associated with alcohol use during pregnancy. Having two or more sex partners was associated with maternal alcohol use $(P<$ $0.001)$. Also respondents who disagreed that their families would not approve of them drinking during pregnancy $(P<0.001)$ and those who agreed that their family and friends would approve of them drinking during pregnancy $(P<0.001)$ were more likely to drink than those who gave other responses. Women with negative attitudes (said alcohol was not all that important and those who said it was slightly important in increasing chances of health risks for women and babies were more likely to $\operatorname{drink}(P<0.001)$. This is shown in Table 3 .

\section{Predictors of alcohol use during pregnancy}

Among socio demographic factors examined, residence was predictive of maternal alcohol use. Women in urban areas were less likely to consume alcohol as compared to those in rural areas (OR 0.39; 95\% CI: 0.17 to 0.91). Level of education was not predictive of alcohol use during pregnancy although women with secondary or higher level of education were more likely to drink $(\mathrm{OR}=2.13$; 95\% CI: 0.42 to 3.21 ).

Also, women with 5 or more children were more likely to drink compared to those with one or no children $(P=0.018 ;$ OR $=5.4 ; 95 \%$ CI: 1.3 to 22.5$)$. This variable was not significant for those with 2, 3, 4 children.

Knowledge and attitude were important predictors of maternal alcohol use in this study. Those who had never received any information about drinking during pregnancy are more likely to drink compared to those who have received the information $(P=0.002$; $\mathrm{OR}=4.08$; 95\% CI 1.6 to 10.1). Respondents who had no knowledge of anything that could harm the baby during pregnancy were less likely to drink $(P=0.004$; OR $=0.24 ; 95 \%$ CI 0.09 to 0.64 ).

Women with positive or fair or positive attitude towards drinking during pregnancy (Said alcohol was moderately important/very important or extremely important in increasing chances of health risks for women and babies) were less likely to drink than those who said alcohol was not at all important in increasing chances of health risks for women and $\operatorname{babies}(P=0.010$; $\mathrm{OR}=0.114$; 95\% CI $=-0.02$ to 0.59 ) Respondents who agreed to the question 'my family would not approve of me drinking while pregnant' were less likely to $\operatorname{drink}(P=0.002$; OR $=$ 0.05 ; $95 \%$ CI 0.009 to 0.34 ). Number of sex partners was not a significant factor in predicting alcohol use during pregnancy although those with 2 or more partners have higher chances of drinking during pregnancy $(\mathrm{OR}=2.6$; $95 \% \mathrm{CI}=0.58$ to 12.0 ). The remaining measures including, age, occupation and marital status all bear no significant association with self-reported alcohol use during pregnancy. These are shown in Table 4.

\section{Predictors of frequent alcohol use and binge drinking Frequent alcohol use}

This study assessed predictors of frequent alcohol use (drinking at least 2 to 3 times a week). Mothers who agreed that 'My Friends and Community would approve of me drinking when pregnant' were more likely to drink 2 to 3 times a week as compared to those who had other responses $(P=0.017 ; \mathrm{OR}=7.95 ; 95 \% \mathrm{CI} 1.45$ to 43.3$)$. Specific knowledge had a bearing on frequent alcohol use during pregnancy. Women were asked to list dangers of alcohol use to the mother and baby during pregnancy. The more dangers they mentioned the more they were likely to drink frequently $(P=0.008 ; \mathrm{OR}=11.2$; $95 \% \mathrm{CI}=1.8$ to 67.0 ). Other variables did not predict frequent alcohol use. This is presented in Table 5.

\section{Binge/heavy drinking}

Predictors of monthly, weekly and daily binge drinking were estimated. The effect of education on the likelihood of binge category was only significant with respect to women with secondary level and higher education $(\mathrm{OR}=$ 16.4; $95 \%$ CI:0.80 to 335.4). The odds ratios show that women with primary education were 6.2 times more likely to binge frequently. On the other hand, those with secondary and higher had 16.4 more odds of belonging to the binge category relative to those with no formal education. General knowledge was also predictive of binging. Those who said they had no knowledge of anything that could harm baby during pregnancy were more likely 
Table 3 Showing factors associated with alcohol use during pregnancy

\begin{tabular}{|c|c|c|c|c|c|c|}
\hline & \multicolumn{4}{|c|}{ Currently Drinking Alcohol } & \multirow[t]{2}{*}{ Chi-square } & \multirow[t]{2}{*}{$p$-value } \\
\hline & No & $\%$ & Yes & & & \\
\hline \multicolumn{7}{|l|}{ Age } \\
\hline $15-20$ & 89 & $80.9 \%$ & 21 & $19.1 \%$ & & \\
\hline $21-25$ & 102 & $81.0 \%$ & 24 & $19.0 \%$ & & \\
\hline $26-30$ & 79 & $75.2 \%$ & 26 & $24.8 \%$ & 12.506 & .014 \\
\hline $31-35$ & 40 & $70.2 \%$ & 17 & $29.8 \%$ & & \\
\hline $36-45$ & 11 & $50.0 \%$ & 11 & $50.0 \%$ & & \\
\hline \multicolumn{7}{|c|}{ Highest Level of Education Attained } \\
\hline No formal education & 26 & $60.5 \%$ & 17 & $39.5 \%$ & & \\
\hline Primary & 189 & $79.7 \%$ & 48 & $20.3 \%$ & 8.032 & .045 \\
\hline Secondary & 78 & $77.2 \%$ & 23 & $22.8 \%$ & & \\
\hline Higher & 28 & $71.8 \%$ & 11 & $28.2 \%$ & & \\
\hline \multicolumn{7}{|c|}{ Ever Consumed Alcohol* } \\
\hline No & 193 & $99.5 \%$ & 1 & $.5 \%$ & 106.382 & $<.000$ \\
\hline Yes & 128 & $56.6 \%$ & 98 & $43.4 \%$ & & \\
\hline \multicolumn{7}{|l|}{ Live Children* } \\
\hline One & 66 & $78.6 \%$ & 18 & $21.4 \%$ & & \\
\hline Two & 78 & $83.9 \%$ & 15 & $16.1 \%$ & 15.403 & .004 \\
\hline Three & 63 & $75.0 \%$ & 21 & $25.0 \%$ & & \\
\hline Four & 24 & $63.2 \%$ & 14 & $36.8 \%$ & & \\
\hline Five+ & 12 & $50.0 \%$ & 12 & $50.0 \%$ & & \\
\hline \multicolumn{7}{|l|}{ Trimester* } \\
\hline First trimester & 94 & $85.5 \%$ & 16 & $14.5 \%$ & & \\
\hline Second trimester & 156 & $69.3 \%$ & 69 & $30.7 \%$ & 13.641 & .001 \\
\hline Third trimester & 71 & $83.5 \%$ & 14 & $16.5 \%$ & & \\
\hline \multicolumn{7}{|l|}{ Religion } \\
\hline Catholic & 190 & $75.4 \%$ & 62 & $24.6 \%$ & & \\
\hline Protestant & 77 & $73.3 \%$ & 28 & $26.7 \%$ & 3.723 & .296 \\
\hline Muslim & 12 & $85.7 \%$ & 2 & $14.3 \%$ & & \\
\hline Pentecostal & 42 & $85.7 \%$ & 7 & $14.3 \%$ & & \\
\hline \multicolumn{7}{|l|}{ Residence } \\
\hline Rural & 177 & $72.8 \%$ & 66 & $27.2 \%$ & & \\
\hline Urban & 131 & $84.0 \%$ & 25 & $16.0 \%$ & 9.127 & .010 \\
\hline Peri urban & 13 & $61.9 \%$ & 8 & $38.1 \%$ & & \\
\hline \multicolumn{7}{|c|}{ Sex Partners they have had in the last twelve months* } \\
\hline One & 304 & $80.2 \%$ & 75 & $19.8 \%$ & & \\
\hline Two to Five & 17 & $42.5 \%$ & 23 & $57.5 \%$ & 31.812 & $<.000$ \\
\hline Six to ten & 0 & $0.0 \%$ & 1 & $100.0 \%$ & & \\
\hline Other & 0 & $0.0 \%$ & 0 & $0.0 \%$ & & \\
\hline \multicolumn{7}{|c|}{ Knowledge of anything that could Harm baby during pregnancy* } \\
\hline Yes & 231 & $80.8 \%$ & 55 & $19.2 \%$ & & \\
\hline No & 90 & $67.2 \%$ & 44 & $32.8 \%$ & 9.375 & .002 \\
\hline
\end{tabular}

Attitude/Perception of Alcohol use during pregnancy in increasing health risks to baby and mother*
Negative attitude
70
$52.2 \%$
64
$47.8 \%$ 
Table 3 Showing factors associated with alcohol use during pregnancy (Continued)

\begin{tabular}{|c|c|c|c|c|c|c|}
\hline & \multicolumn{4}{|c|}{ Currently Drinking Alcohol } & \multirow[t]{2}{*}{ Chi-square } & \multirow[t]{2}{*}{$p$-value } \\
\hline & No & $\%$ & Yes & & & \\
\hline Fair attitude & 48 & $82.8 \%$ & 10 & $17.2 \%$ & 64.927 & $<.000$ \\
\hline Positive attitude & 203 & $89.0 \%$ & 25 & $11.0 \%$ & & \\
\hline \multicolumn{7}{|c|}{ My Family would not approve of me drinking while pregnant* } \\
\hline Strongly disagree & 10 & $76.9 \%$ & 3 & $23.1 \%$ & & \\
\hline Disagree & 7 & $15.2 \%$ & 39 & $84.8 \%$ & 111.843 & $<.000$ \\
\hline Agree & 216 & $81.5 \%$ & 49 & $18.5 \%$ & & \\
\hline Strongly Agree & 88 & $91.7 \%$ & 8 & $8.3 \%$ & & \\
\hline \multicolumn{7}{|c|}{ My Friends and Community would approve of me drinking when pregnant* } \\
\hline Strongly disagree & 77 & $95.1 \%$ & 4 & $4.9 \%$ & & \\
\hline Disagree & 226 & $78.7 \%$ & 61 & $21.3 \%$ & & \\
\hline Agree & 15 & $31.3 \%$ & 33 & $68.8 \%$ & 70.853 & $<.000$ \\
\hline Strongly Agree & 3 & $75.0 \%$ & 1 & $25.0 \%$ & & \\
\hline \multicolumn{7}{|c|}{ Ever received Information on drinking during pregnancy* } \\
\hline Yes & 228 & $88.0 \%$ & 31 & $12.0 \%$ & 50.486 & $<.000$ \\
\hline No & 93 & $57.8 \%$ & 68 & $42.2 \%$ & & \\
\hline
\end{tabular}

${ }^{*} p<0.05$ are variables significant at $5 \%$

Significant bivariate variables included pre-pregnancy alcohol consumption, having live children knowledge, attitudes, number of sex partners and trimester of pregnancy

to binge frequently $(P=0.004 ; \mathrm{OR}=14.8 ; 95 \% \mathrm{CI} 2.32$ to 94.9). Women who agreed that 'My Family would not approve of me drinking while pregnant were less likely to binge frequently than those who gave other responses $(P=0.04$; OR $=0.2 ; 95 \%$ CI 0.04 to 0.93$)$. This is shown in Table 6 .

\section{Discussion}

In this cross sectional study of 420 women seeking antenatal care in selected health facilities in Gulu, Kitgum and Pader districts in post conflict Northern Uganda, 23.6\% reported current maternal alcohol use (any amount), 194 (46.2\%) reported lifetime alcohol abstinence and 33 women reportedly abandoned alcohol use on pregnancy recognition.

The relatively high $(23.6 \%)$ proportion of maternal alcohol use reported in this study could be attributed to availability of cheap alcoholic beverages that are served on various functions such as market days and clan gatherings. Being a post conflict environment, this region also experienced scale up of alcohol promotions as new markets opened up and both local and international alcohol companies sought to expanded their clientele [7, 37].

The prevalence of alcohol use during the current pregnancy in this study is higher than the proportion (16\%) reported in western Uganda [38] and almost the same as the proportions (25\%) reported among urban women in Kampala [27]. This proportion is also much lower than the $59.28 \%$ reported by pregnant Nigerian women [19].
It is higher than the reported 10 and $15 \%$ of pregnant women in Canada and the United States [39].

Binge drinking and frequent drinking were less commonly reported by pregnant mothers in this study. This is disimilar to other studies conducted in conflicted affected regions where Alcohol Use Disorder has been reportedly common [37]. Binge drinking is occasionally done during festivities and thus not as common. This is not surprising as related studies reported binge drinking during pregnancy to range from 0.2 to $13.9 \%$ [40]. In a recent study in Zambia, pregnant women at risk of problem drinking were $21.2 \%$ [35].

Knowledge and attitude were important predictors of alcohol use during pregnancy. Women who agreed to the question my Family would not approve of me drinking while pregnant were less likely to drink while those who agreed to the statement that My friends and Community would approve of me drinking when pregnant were more likely to drink. This relates to study in a tribal dominated district among pregnant Indian women who reportedly were unable to stop drinking during pregnancy because it was generally accepted by their communities [36]. Interventions seeking to reduce alcohol use during pregnancy should target not only pregnant women but generally women in the reproductive age group and their influencers such as family members and significant others.

Other post conflict related studies have also reported alcohol use as form of self- medication or coping strategy. This is aggravated by poor living conditions and 
Table 4 Showing predictors of alcohol use during pregnancy

\begin{tabular}{ll}
\hline Variable & OR $(\mathbf{9 5 \%} \mathbf{C l})$ \\
\hline $\begin{array}{l}\text { Level of Education } \\
\text { No formal education (Ref) }\end{array}$ & \\
$\quad$ Primary & $0.9(0.3$ to 2.9$)$ \\
$\quad$ Secondary & $2.13(0.51$ to 8.8$)$ \\
Living Children & \\
One (Ref) & \\
Two & $1.2(0.42$ to 3.2$)$ \\
Three & $1.79(0.66$ to 4.8$)$ \\
Four & $3.3(0.95$ to 11.9$)$ \\
Five and more & $5.4(1.3 \text { to } 22.5)^{*}$
\end{tabular}

\section{Residence}

Rural (Ref)

Urban

Peri urban

$0.3(0.17$ to 0.91$)$

0.1 (0.019 to 0.84$)$

Sex Partners in last Twelve Months

One (Ref)

Two or more

1.9 (0.6 to 6.5$)$

Knowledge of Anything that Could Harm Baby during Pregnancy Yes (Ref)
No
$0.2(0.09 \text { to } 0.64)^{*}$

Attitude towards Alcohol Use During Pregnancy

Negative (Ref)
Fair attitude
0.2 (0.05 to 0.65$)$
Positive attitude
$0.16(0.05 \text { to } 0.4)^{*}$

My Family would not approve of me drinking while pregnant Disagree (Ref)
Agree
$0.1(0.04 \text { to } 0.36)^{*}$

My Friends and Community would approve of me drinking when pregnant

Disagree (Ref)

Agree 2.46 (0.84 to 7.1 )

Ever received Information on drinking during pregnancy Yes (Ref)
No
4.1 (1.64 to 10.1.)

Knowledge of Dangers of Alcohol Use during Pregnancy

Number of dangers

2.02 (0.7 to 5.6)

Number of Observations $=314$

LR chi2 (16) $=127.05$

Prob $>$ chi $2=0.0000$

${ }^{*} p<0.05$

Insignificant bivariate variables were not included in the model: Age,

education and religion
Table 5 Showing predictors of frequent drinking

\begin{tabular}{ll}
\hline Variable & OR(95\% Cl) \\
\hline $\begin{array}{l}\text { Level of Education } \\
\text { No formal education (Ref) }\end{array}$ & \\
$\quad$ Primary & $0.9(0.09$ to 9.5$)$ \\
$\quad$ Secondary & $1.3(0.06$ to 24.5$)$ \\
$\quad$ Higher & $0.8(0.03$ to 22.5$)$
\end{tabular}

\section{Living Children}

One (Ref)

$\begin{array}{ll}\text { Two } & 1.2(0.19 \text { to } 7.6) \\ \text { Three } & 2.3(0.36 \text { to } 15.5) \\ \text { Four } & 1.6(0.20 \text { to } 13.0) \\ \text { Five and more } & 0.36(0.014 \text { to } 9.2)\end{array}$

Residence

Rural (Ref)

Urban $\quad 0.4$ (0.08 to 2.27)

Peri urban $\quad 0.3$ (0.01 to 6.5)

Sex Partners in last Twelve Months

One (Ref)

Two or more 2.6 (0.4 to 13.2)

Knowledge of Anything that Could Harm Baby during Pregnancy Yes (Ref)

No $\quad 0.5$ (0.1 to 2.6$)$

Attitude towards Alcohol Use During Pregnancy

Negative (Ref)

Fair attitude $\quad 1.3$ (0.14 to 12.7 )

Positive attitude $\quad 1.21$ (0.14 to 10.5 )

My Family would not approve of me drinking while pregnant Disagree (Ref)
Agree
$2.3(0.47$ to 11.3$)$

My Friends and Community would approve of me drinking when pregnant

Disagree (Ref)

Agree $\quad 7.9(1.45 \text { to } 43.3)^{*}$

Ever received Information on drinking during pregnancy

Yes (Ref)

No $\quad 1.2$ (0.22 to 6.74)

Knowledge of Dangers of Alcohol Use during Pregnancy No (Ref)

Number of dangers $\quad 11.2(1.8 \text { to } 67.02)^{*}$

Number of Observations $=80$

LR chi2 (17) $=32.41$

Prob $>$ chi2 $=0.0134$

Pseudo R2 $=0.2956$

${ }^{*} p<0.05$

Significant variables for frequent drinking included knowledge and attitude 
Table 6 Showing predictors of binge drinking

\begin{tabular}{ll}
\hline Variable & OR $(95 \%$ Cl) \\
\hline $\begin{array}{l}\text { Level of Education } \\
\quad \text { Primary }\end{array}$ & \\
$\quad$ Secondary & $16.4(0.61$ to 63.8$)$ \\
Living Children & \\
One (Ref) & \\
Two & $0.13(0.02$ to 1.28$)$ \\
Three & $0.14(0.02$ to 1.38$)$ \\
Four & $0.09(0.01$ to 1.06$)$ \\
Five and more & $0.1(0.01$ to 2.32$)$ \\
Residence & \\
Rural (Ref) & \\
Urban & $1.5(0.32$ to 11.9$)$ \\
Peri urban & $0.03(0.00$ to 4.31$)$ \\
Sex Partners in last Twelve Months & \\
One (Ref) & \\
Two or more & $3.4(0.6$ to 16.4$)$
\end{tabular}

Knowledge of Anything that Could Harm Baby during Pregnancy Yes (Ref)

No

$14.8(2.32 \text { to } 94.9)^{*}$

Attitude towards Alcohol Use During Pregnancy

Negative (Ref)

Fair attitude

1.16 (0.03 to 7.17$)$

Positive attitude

8.4 (0.91 to 107.4)

My Family would not approve of me drinking while pregnant Disagree (Ref)

Agree

$0.2(0.04 \text { to } 0.93)^{*}$

My Friends and Community would approve of me drinking when pregnant

Disagree (Ref)

Agree $\quad 0.5$ (0.11 to 2.67 )

Ever received Information on drinking during pregnancy Yes (Ref)

No 2.8 (0.46 to 17.7 )

Knowledge of Dangers of Alcohol Use during Pregnancy

No (Ref)

Number of dangers 0.49 (0.08 to2.93)

Number of observations $=80$

LR chi2 (17) $=27.39$

Prob $>$ chi2 $=0.0374$

Pseudo R2 $=0.3031$

${ }^{*} p<0.05$

Variables that predicted binge drinking included knowledge and attitude challenges in accessing healthcare [41]. Healthcare workers should make deliberate efforts to identify women abusing alcohol due to trauma and provide them with counseling.

There seems to be a paradoxical relationship between specific knowledge and maternal alcohol use in this study. The more dangers of alcohol use during pregnancy a respondent cited the more they were likely to drink. Perhaps some for these women had reached addiction stage and are unable to control their drinking or that alcohol being a social drink they could be receiving information on alcohol use from their social networks such as drinking places. Also, these women may not have been victims of the dangers of drinking during pregnancy. These results are similar to what was found among Canadian women for whom specific knowledge including knowledge that drinking during pregnancy can lead to lifelong disabilities in a child predicted maternal drinking [24]. But also, adequate knowledge (mentioned 4 or more effects of alcohol on mother and baby) was reported by very few $(N=10,2.4 \%)$. The high levels of ignorance of repercussions of drinking during pregnancy might be responsible for high levels of alcohol use during pregnancy.

Health workers were the most common source of information on dangers of drinking during pregnancy $(N=178,75.1 \%)$ followed by friends $(N=65,27.4 \%)$. This is higher than $33.5 \%$ of pregnant women in Ghana who got information on maternal drinking in ANC clinics [20] and $62.29 \%$ women told by a health professional in Nigeria [19]. Whereas this statistic is impressive, it falls short of expectation that all pregnant women seeking care at health facilities should be educated about all possible risks of harm to pregnancy including alcohol use.

Strengths of our study are that it has a large sample size and provides contemporaneous prevalence data on alcohol use during pregnancy in a post conflict setting and investigates predictors of alcohol use (any amount), frequent and heavy drinking. However, this study has some limitations, it was a cross sectional study thus cause and effect could not be established. Also, this study could have been affected by under reporting due to social desirability and recall bias. Most of the alcohol consumed was locally brewed and for some of the homemade brews, the alcohol by volume is unknown so it was hard to convert them into the US standard drink. None the less, literature maintains that there is no safe amount of alcohol consumption during pregnancy. Some confidence intervals were very wide perhaps because some responses had few observations such as women who never consumed alcohol before pregnancy but started consuming after pregnancy recognition. We recommend future studies to explore this further. 


\section{Conclusion and recommendations}

This study indicated that alcohol use (any mount) during pregnancy is high while alcohol dependence, problematic and hazardous drinking is low. Knowledge and attitude were important predictors of alcohol use. While alleviating alcohol use, development partners and relevant government departments should consider interventions that increase knowledge and risk perception on maternal drinking. Other risk factors that predict maternal drinking such as prior alcohol use, residence and parity should be mitigated or eliminated. Interventions seeking to reduce alcohol use during pregnancy should target not only pregnant women but generally women in the reproductive age group and their influencers such as family members and significant others.

Given that this is one of a few studies that have assessed drinking during pregnancy in a post conflict area, the results call for urgent attention to the need for specifically targeted interventions to reduce alcohol use among women of child bearing age and pregnant women in particular. This will reduce related risks to the mother and the baby.

\section{Abbreviations}

ABV: Alcohol by Volume; ANC: Antenatal Care; AUDIT: Alcohol Use Disorders Identification Test; DHO: District Health Officer; FASD: Fetal Alcohol Spectrum Disorders; LBW: Low Birth Weight; LRA: Lord's Resistance Army; ODK: Open Data Kit; OR: Odds Ratio; PTB: Preterm Births; SPSS: Statistical Package for Social Sciences; UNCST: Uganda National Council for Science and Technology; WHO: World Health Organization

\section{Acknowledgements}

We would like to thank the data collectors, staff in the district health departments in Gulu, Kitgum and Pader and health workers at facilities where the study was conducted. We would also like to extend our deepest gratitude to the pregnant women who participated in the study without whom this research wouldn't have been possible.

\section{Authors' contributions}

AA, NMT and GN conceived and designed the study. AA, NMT GN, EN, GWM and JK contributed to proposal development. AA Conducted the analysis and wrote the first draft of the paper. All authors contributed to writing of the paper. The authors read and approved the final manuscript.

\section{Funding}

It was funded by the Makerere University RFI grant. They had no role in data collection, management or report writing.

\section{Availability of data and materials}

All relevant data are within the paper. If further data needed, it could be accessed from the first author upon request via email at agiresaasi@gmail. com.

\section{Ethics approval and consent to participate}

This study was approved by the Makerere University School of Public Health Institutional Review Board and the Uganda National Council for Science and Technology (UNCST) Ref SS 4938. Study participants were assured of the confidentiality of their responses and their written informed consent was sought before the interviews commenced. They were informed that they could choose not to answer any questions that they were not comfortable with or could withdraw from the interview at any time. In addition, the study sought clearance from the office of the District Health Officers (DHO) in each of the three districts of Gulu, Kitgum and Pader.

\section{Consent for publication}

All authors approved the final version for publication.

\section{Competing interests}

The authors declare that they have no competing interests.

\section{Author details}

${ }^{1}$ College of Health Sciences, Makerere School of Public Health, Kampala, Uganda. ${ }^{2}$ Department of Journalism and Communication, College of Humanities and Social Sciences, Kampala, Uganda.

Accepted: 11 December 2020

Published online: 04 January 2021

\section{References}

1. Organization WH. Global status report on alcohol and health 2018: World Health Organization; 2019.

2. Kabwama SN, Ndyanabangi S, Mutungi G, Wesonga R, Bahendeka SK, Guwatudde D. Alcohol use among adults in Uganda: findings from the countrywide non-communicable diseases risk factor cross-sectional survey. Glob Health Action. 2016:9(1):31302.

3. Tumwesigye NM, Kasirye R. Gender and the major consequences of alcohol consumption in Uganda. Alcohol Gender Drink Prob. 2005;189:189-280.

4. Roberts B, Ocaka KF, Browne J, Oyok T, Sondorp E. Alcohol disorder amongst forcibly displaced persons in northern Uganda. Addict Behav. 2011;36(8):870-3.

5. Khasalamwa-Mwandha S. Geographical versus social displacement: the politics of return and post-war recovery in northern Uganda. Dev Pract. 2019:29(3):314-25.

6. Nannyonjo J. Conflicts, poverty and human development in northern Uganda. Round Table. 2005;94(381):473-88.

7. Blair AH, Pearce ME, Katamba A, Malamba SS, Muyinda H, Schechter MT, et al. The alcohol use disorders identification test (AUDIT): exploring the factor structure and cutoff thresholds in a representative post-conflict population in northern Uganda. Alcohol Alcohol. 2017;52(3):318-27.

8. Ssebunnya J, Kituyi C, Nabanoba J, Nakku J, Bhana A, Kigozi F. Social acceptance of alcohol use in Uganda. BMC Psychiatry. 2020;20(1):1-7.

9. Bank W. Uganda Poverty Assessment 2016. 2016.

10. Popova S, Lange S, Probst C, Gmel G, Rehm J. Estimation of national, regional, and global prevalence of alcohol use during pregnancy and fetal alcohol syndrome: a systematic review and meta-analysis. Lancet Glob Health. 2017;5(3):e290-e9.

11. Popova S, Lange S, Probst C, Gmel G, Rehm J. Global prevalence of alcohol use and binge drinking during pregnancy, and fetal alcohol spectrum disorder. Biochem Cell Biol. 2018:96(2):237-40.

12. Organization WH. Global status report on noncommunicable diseases 2014. Switzerland: World Health Organization; 2014.

13. Croxford J, Viljoen D. Alcohol consumption by pregnant women in the Western Cape. South Afr Med J. 1999:89(9):1-4.

14. Jones HE, Browne FA, Myers BJ, Carney T, Ellerson RM, Kline TL, et al. Pregnant and nonpregnant women in Cape Town, South Africa: drug use, sexual behavior, and the need for comprehensive services. Int J Pediatr. 2011;2011.

15. Matseke G, Peltzer K, Mlambo G. Partner violence and associated factors among pregnant women in Nkangala district, Mpumalanga. South Afr J Obstet Gynaecol. 2012;18(3)77-81.

16. Etukumana E, Thacher T, Sagay A. HIV risk factors among pregnant women in a rural Nigerian hospital. West Indian Med J. 2010:59(4):424-33.

17. Ezugwu E, Ohayi S, Okeke T, Dim C. HIV sero-prevalence among pregnant women in a resource constrained setting, south East Nigeria. Niger J Med. 2012;21(3):338-42.

18. Fawole $\mathrm{AO}$, Hunyinbo $\mathrm{Kl}$, Fawole Ol. Prevalence of violence against pregnant women in Abeokuta, Nigeria. Aust N Z J Obstet Gynaecol. 2008; 48(4):405-14.

19. Ordinioha B, Brisibe S. Alcohol consumption among pregnant women attending the ante. Natal clinic of a tertiary hospital in south. South Nigeria. Niger J Clin Pract. 2015;18(1):13-7.

20. Adusi-Poku Y, Edusei AK, Bonney AA, Tagbor H, Nakua E, Otupiri E. Pregnant women and alcohol use in the Bosomtwe district of the Ashanti regionGhana. Afr J Reprod Health. 2012;16(1):55-60. 
21. Yoon HJ, Bonsu G, Akoto-Ampaw A, Nkrumah-Mills G, Nimo JJ, Park JK, et al. Prevalence and risk factors for human immunodeficiency virus infection in pregnant women in eastern Ghana. Braz J Infect Dis. 2012;16(2):217-8.

22. Mpelo M, Kibusi SM, Moshi F, Nyundo A, Ntwenya JE, Mpondo BC. Prevalence and factors influencing alcohol use in pregnancy among women attending antenatal care in Dodoma region, Tanzania: a crosssectional study. J Pregnancy. 2018;2018. https://www.hindawi.com/journals/ jp/2018/8580318.

23. Anteab K, Demtsu B, Megra M. Assessment of prevalence and associated factors of alcohol use during pregnancy among the dwellers of Bahir-Dar City, Northwest Ethiopia, 2014; 2014.

24. Peadon E, Payne J, Henley N, D'antoine H, Bartu A, O'Leary C, et al. Women's knowledge and attitudes regarding alcohol consumption in pregnancy: a national survey. BMC Public Health. 2010;10(1):510.

25. Adeyiga G, Udofia EA, Yawson AE. Factors associated with alcohol consumption: a survey of women childbearing at a national referral hospital in Accra, Ghana. Afr J Reprod Health. 2014;18(2):152-65.

26. Desmond K, Milburn N, Richter L, Tomlinson M, Greco E, Van Heerden A, et al. Alcohol consumption among HIV-positive pregnant women in KwaZulu-Natal, South Africa: prevalence and correlates. Drug Alcohol Depend. 2012;120(1-3):113-8.

27. Namagembe I, Jackson LW, Zullo MD, Frank SH, Byamugisha JK, Sethi AK. Consumption of alcoholic beverages among pregnant urban Ugandan women. Matern Child Health J. 2010;14(4):492-500.

28. Harrison PA, Sidebottom AC. Alcohol and drug use before and during pregnancy: an examination of use patterns and predictors of cessation. Matern Child Health J. 2009;13(3):386.

29. Iversen ML, Sørensen NO, Broberg L, Damm P, Hedegaard M, Tabor A, et al. Alcohol consumption and binge drinking in early pregnancy. A crosssectional study with data from the Copenhagen Pregnancy Cohort. BMC Pregnancy Childbirth. 2015;15(1):327.

30. Hotham E, Ali R, White J, Robinson J. Pregnancy-related changes in tobacco, alcohol and cannabis use reported by antenatal patients at two public hospitals in South Australia. Aust N Z J Obstet Gynaecol. 2008;48(3):248-54.

31. Tamaki T, Kaneita Y, Ohida T, Harano S, Yokoyama E, Osaki Y, et al. Alcohol consumption behavior of pregnant women in Japan. Prev Med. 2008;47(5): 544-9.

32. Yamamoto Y, Kaneita Y, Yokoyama E, Sone T, Takemura S, Suzuki K, et al. Alcohol consumption and abstention among pregnant Japanese women. J Epidemiol. 2008;18(4):173-82

33. Zammit SL, Skouteris H, Wertheim EH, Paxton SJ, Milgrom J. Pregnant women's alcohol consumption: the predictive utility of intention to drink and prepregnancy drinking behavior. J Womens Health. 2008;17(9):1513-22.

34. Conigrave KM, Saunders JB, Reznik RB. Predictive capacity of the AUDIT questionnaire for alcohol-related harm. Addiction. 1995;90(11):1479-85.

35. Saunders JB, Aasland OG, Babor TF, De la Fuente JR, Grant M. Development of the alcohol use disorders identification test (AUDIT): WHO collaborative project on early detection of persons with harmful alcohol consumption-II. Addiction. 1993;88(6):791-804 35.Moise IK. Alcohol use, pregnancy and associated risk factors: a pilot cross-sectional study of pregnant women attending prenatal care in an urban city. BMC pregnancy and childbirth. 2019 Dec 1;19(1):472.3.

36. Babor TF. Typology of drinkers. 1992. 36.Pati S, Chauhan AS, Mahapatra P, Hansdah D, Sahoo KC, Pati S. Weaved into the cultural fabric: a qualitative exploration of alcohol consumption during pregnancy among tribal women in Odisha, India. Substance abuse treatment, prevention, and policy. 2018 Dec;13(1):9.

37. Wallace K, Roberts B. An exploration of the alcohol policy environment in post-conflict countries. Alcohol Alcohol. 2014;49(3):356-62.

38. English L, Mugyenyi G, Nightingale I, Kiwanuka G, Ngonzi J, Grunau B, et al. Prevalence of ethanol use among pregnant women in southwestern Uganda. Matern Child Health J. 2016;20(10):2209-15.

39. Popova S, Lange S, Probst C, Parunashvili N, Rehm J. Prevalence of alcohol consumption during pregnancy and fetal alcohol Spectrum disorders among the general and Aboriginal populations in Canada and the United States. Eur J Med Genet. 2017;60(1):32-48.

40. Lange S, Probst C, Rehm J, Popova S. Prevalence of binge drinking during pregnancy by country and World Health Organization region: systematic review and meta-analysis. Reprod Toxicol. 2017;73:214-21.
41. Rehm J, Mathers C, Popova S, Thavorncharoensap M, Teerawattananon Y, Patra J. Global burden of disease and injury and economic cost attributable to alcohol use and alcohol-use disorders. Lancet. 2009;373(9682):2223-33.

\section{Publisher's Note}

Springer Nature remains neutral with regard to jurisdictional claims in published maps and institutional affiliations.
Ready to submit your research? Choose BMC and benefit from:

- fast, convenient online submission

- thorough peer review by experienced researchers in your field

- rapid publication on acceptance

- support for research data, including large and complex data types

- gold Open Access which fosters wider collaboration and increased citations

- maximum visibility for your research: over $100 \mathrm{M}$ website views per year

At $\mathrm{BMC}$, research is always in progress.

Learn more biomedcentral.com/submissions 